\title{
Comparison of Different Techniques of Pancreatic Stump Management in Robot- Assisted Pancreaticoduodenectomy
}

\author{
Raquel Gonzalez-Heredia Samarth Durgam Mario Masrur \\ Luis Fernando Gonzalez-Ciccarelli Antonio Gangemi \\ Francesco M. Bianco Pier C. Giulianotti \\ Division of General, Minimally Invasive, and Robotic Surgery, Department of Surgery, \\ University of Illinois at Chicago, Chicago, IL, USA
}

\author{
Keywords \\ Postoperative pancreatic fistula - Pancreatic stump management · Robot-assisted \\ pancreaticoduodenectomy
}

\begin{abstract}
Background: Various technical improvements have decreased the morbidity and mortality after pancreaticoduodenectomy. However, postoperative pancreatic fistula (POPF) is the most feared complication, and the ideal technique for pancreatic reconstruction is undetermined. The aim of this study was to identify the risk factors and incidence of POPF with different types of pancreatic stump management after robot-assisted pancreaticoduodenectomy (RAPD). Materials and Methods: This study is a retrospective review of consecutive patients who underwent RAPD at the University of Illinois Hospital and Health Sciences System between September 2007 and January 2016. The cohort was divided based on the type of pancreatic stump management: pancreatic duct occlusion with cyanoacrylate glue (CG), pancreaticojejunostomy (PJ), posterior pancreaticogastrostomy (PPG), and transgastric pancreaticogastrostomy (TPG). Results: The cohort included 69 patients: pancreatic duct occlusion with CG $(n=18)$, PJ $(n=12)$, PPG $(n=11)$, and TPG $(n=28)$. Pancreatic duct diameter $<3 \mathrm{~mm}$ and duct occlusion with CG were identified as risk factors for POPF $(p<0.05)$. The incidence of POPF was lower when TPG and PJ were performed $(p<0.001)$. Conclusions: Reconstruction with PJ and TPG had better results compared to pancreatic duct occlusion with CG and PPG. However, TPG was the technique of choice and showed comparable results to PJ.




\section{Introduction}

Pancreaticoduodenectomy (PD) is the surgical treatment of choice for malignant or benign disease of the pancreatic head and periampullary region [1]. With improvements in operative techniques and perioperative management, mortality has decreased to $<5 \%$ in high-volume centers [2-4]. However, morbidity remains high. Postoperative pancreatic fistula (POPF) is the most feared complication, with an incidence of 8-26\% [5-7] and a specific mortality of up to $8 \%$ [8]. Friable texture of the pancreas, small pancreatic duct diameter, high operative blood loss, and high body mass index have been identified as risk factors for POPF, both in open and minimally invasive PD [9-11]. Surgical management of the pancreatic stump is an important aspect of the procedure, as pancreatic anastomotic failure represents the main cause of POPF $[12,13]$. Several techniques have been suggested in order to reduce the incidence of POPF, including pancreaticogastrostomy (PG), isolated loop pancreaticojejunostomy (PJ), transgastric pancreaticogastrostomy (TPG), and duct to mucosa or invagination in PJ [14-17]. Nonetheless, no single pancreatic reconstruction technique has been proven to be superior to others [18]. Moreover, management of the pancreatic stump often varies based on intraoperative findings and the surgeon's experience. As a result, the anastomotic technique and its association with POPF still remain unclear [13].

In the last decade, minimally invasive techniques, such as laparoscopy and robotic surgery, have shown outcomes comparable to those of open PD [19-21]. The inherent limitations of the laparoscopic approach have been a barrier to its widespread adoption [22]. The robotic platform has emerged as an alternative approach to laparoscopic surgery, and more so with complex procedures like PD, first performed by Giulianotti et al. in 2001 [23].

The aim of this study was to identify the risk factors for POPF after robot-assisted PD (RAPD). Furthermore, we evaluated the incidence of POPF with different types of pancreatic stump management. We hypothesized that TPG reconstruction has a lower rate of POPF than PJ.

\section{Materials and Methods}

This study is a retrospective review of a prospectively maintained database. Data were collected from all consecutive RAPDs performed by a single surgeon at the University of Illinois Hospital and Health Sciences System between September 2007 and January 2016. This study was conducted after institutional review board approval. All patients 18 years of age or older who underwent RAPD were included in this study.

The cohort was divided into four groups according to the type of pancreatic stump management performed. The type of pancreatic stump management was decided on by the surgeon intraoperatively based on the diameter of the pancreatic duct, the consistency of the pancreas (friable vs. hard), associated patient characteristics and comorbidities (demographics, American Society of Anesthesiologists [ASA] score), and surgeon's surgical experience. All of the procedures in our cases were performed by the same experienced surgeon, who had long overcome his learning curve with thousands of laparoscopic and open procedures. At the beginning of the surgeon's robotic experience, cases were managed by pancreatic duct occlusion using cyanoacrylate glue (CG) to avoid any possible serious complications related to the pancreatic anastomosis. PG was used to decrease POPF rates. Subsequently, PJ was preferred when the texture of the pancreas was hard and the duct diameter was $\geq 3 \mathrm{~mm}$. The TPG technique was favored in cases with a small pancreatic duct and friable pancreas. Prior to implementing the TPG technique, posterior pancreaticogastrostomy (PPG) was the choice in the case of small pancreatic duct and friable pancreatic texture. Demographics, ASA score, diagnosis, as well as intraoperative and postoperative data were analyzed. All fistulas were classified according to the International Study Group of Pancreatic Fistula guidelines [24]. The incidence of POPF and its association with various risk factors and types of pancreatic stump management were analyzed. 
Surgical Technique for the Different Pancreatic Stump Managements

Injection of CG. The pancreatic duct is cannulated and a purse string suture is applied around the pancreatic duct with a nonabsorbable suture. Next, 2-3 mL of CG is injected into the duct. The duct is then ligated with a 3-0 silk suture and the purse string is tied. Interrupted stitches are then placed across the transected pancreatic edge to ensure a better hemostatic seal of the pancreatic stump. Two PJ drains are placed adjacent to the stump to allow for drainage in the event of a pancreatic fistula. Peripancreatic drains are kept in place until the output of the fistula decreases to $<30 \mathrm{~mL} /$ day.

Pancreaticojejunostomy. The first jejunal loop is brought up in a retrocolic and retromesenteric fashion. The pancreatic duct is stented and an end-to-side PJ is then performed. If the diameter of the pancreatic duct is $\geq 3 \mathrm{~mm}$, a mucosa-to-mucosa anastomosis is performed. First, interrupted 4-0 PDS ${ }^{\circledR}$ sutures are placed in the posterior row to attach the pancreatic capsule to the jejunal serosa. A small enterotomy is then made and one row of interrupted stitches of 4-0 PDS ${ }^{\circledR}$ sutures is used. An anterior row of interrupted 4-0 PDS ${ }^{\circledR}$ sutures is then used to seal the pancreatic capsule to the jejunal serosa. If the pancreatic duct does not allow for a mucosa-to-mucosa anastomosis, an anastomosis with the pancreatic parenchyma is performed with a running 4-0 Prolene ${ }^{\circledR}$ suture. The anastomosis is then reinforced using interrupted stitches as a second layer between the pancreatic capsule and the jejunal serosa.

Posterior Pancreaticogastrostomy. After stenting the pancreatic duct, the pancreatic stump is anastomosed to the posterior wall of the stomach. The anterior and posterior row are closed with running 4-0 PDS ${ }^{\circledR}$ sutures and interrupted 4-0 Prolene ${ }^{\circledR}$ stitches for reinforcement.

Transgastric Pancreatic Reconstruction. After completion of the uncinate process dissection, the pancreatic stump is mobilized for at least 1.5-2 inches. A small opening is then created on the posterior gastric wall, ensuring it is at least one-third smaller than the diameter of the pancreatic stump. Two stay sutures are placed on the upper and lower margins of the pancreas. Subsequently, a longitudinal anterior gastrostomy is performed and the stump is gently pulled inside the gastric cavity, ensuring that an adequate invagination is achieved. The pancreatic capsule is anchored to the gastric mucosa with interrupted stitches of 4-0 PDS ${ }^{\circledR}$. Reinforcing sutures are applied if evidence of bleeding is present. The anterior gastrostomy is closed with a running suture of 3-0 PDS $^{\circledR}$.

\section{Statistical Analysis}

Data analyses were conducted using SPSS 22.0 (IBM, SPSS Statistics) and SAS 9.4 (SAS Institute Inc., Cary, NC, USA). Comparisons across groups were performed using analysis of variance for continuous variables. Fisher's exact test was performed on categorical variables. Logistic regression analysis was performed to study the association between POPF and selected predictors. Pearson correlation analysis was performed to examine the association between the risk factors and the pancreatic reconstruction techniques. Confidence intervals were set at $95 \%$ and a two-sided $p$ value $<0.05$ was considered statistically significant.

\section{Results}

A total of 69 patients were included in the study and analyzed. The cohort comprised 37 males $(53.6 \%)$ and 32 females (46.4\%) with a mean age of $61.8 \pm 13.3$ years and a mean body mass index of $26.8 \pm 5.2$. As shown in Table 1, the cohort was divided into four groups based on the type of pancreatic stump management. Eighteen cases underwent CG occlusion of the pancreatic duct, 12 cases underwent PJ, 11 cases underwent PPG, and 28 cases underwent TPG. Cases of concomitant islet cell transplantation, cases with totalization after distal pancreatectomy, and cases converted to open surgery were excluded from the study. The statistical analysis revealed no significant differences in patients' comorbidities across the four groups $(p>0.05)$.

POPF was diagnosed in 13 patients, with an overall incidence of $18.8 \%$. Grade A POPF occurred in 3 cases (4.3\%), grade B in $8(11.6 \%)$, and grade C in $2(2.9 \%)$. 
Table 1. Patient demographics and preoperative data

\begin{tabular}{llllcl}
\hline & $\begin{array}{l}\text { CG occlusion } \\
(n=18)\end{array}$ & $\begin{array}{l}\text { PJ } \\
(n=12)\end{array}$ & $\begin{array}{l}\text { PPG } \\
(n=11)\end{array}$ & $\begin{array}{l}\text { TPG } \\
(n=28)\end{array}$ & $p$ value \\
\hline $\begin{array}{l}\text { Age, years } \\
\text { Sex }\end{array}$ & $64.4 \pm 11.8$ & $65.0 \pm 13.4$ & $54.9 \pm 16.8$ & $54.9 \pm 16.8$ & 0.229 \\
$\quad$ Male & 10 & 6 & 4 & 12 & 0.759 \\
$\quad$ Female & 8 & 6 & 7 & 16 & 0.542 \\
Body mass index & $27.6 \pm 5.4$ & $24.8 \pm 4.4$ & $26.8 \pm 6.2$ & $27.0 \pm 4.9$ & 0.704 \\
ASA score & 0 & 0 & 0 & 1 & 18 \\
$\quad 1$ & 10 & 5 & 5 & 9 & \\
2 & 8 & 7 & 6 & & \\
3
\end{tabular}

ASA, American Society of Anesthesiologists; CG, cyanoacrylate glue; PJ, pancreaticojejunostomy; PPG, posterior pancreaticogastrostomy; TPG, transgastric pancreaticogastrostomy.

Table 2. Results of logistic regression in POPF

\begin{tabular}{llll}
\hline & OR & $95 \%$ CI & $p$ value \\
\hline Age & 1.034 & $0.983-1.0878$ & 0.200 \\
Body mass index & 1.070 & $0.953-1.202$ & 0.253 \\
Operative time & 0.996 & $0.989-1.003$ & 0.297 \\
Estimated blood loss & 1.001 & $0.999-1.003$ & 0.448 \\
\hline
\end{tabular}

$\mathrm{CI}$, confidence interval; OR, odds ratio; POPF, postoperative pancreatic fistula.

\section{Risk Factors for POPF}

A logistic regression model with a univariate predictor was conducted to assess the association between POPF and each of the continuous variables (demographics, operative time, and estimated blood loss) separately. No variable was identified as a significant predictor for POPF (Table 2).

As summarized in Table 3, Fisher's exact test was conducted to analyze the association between POPF and the following categorical variables: ASA score, pancreatic tissue consistency, CG occlusion of the pancreatic duct, and pancreatic duct diameter. A pancreatic duct diameter $<3 \mathrm{~mm}$ and $\mathrm{CG}$ occlusion of the pancreatic duct were identified as risk factors for POPF ( $p=0.014$ and $p<0.001$, respectively). The rate of POPF increased from $0 \%(0 / 19)$ to $26 \%(13 / 50)$ in the cases with pancreatic duct diameter $<3 \mathrm{~mm}$.

\section{Association of Type of Pancreatic Stump Management with the Incidence of POPF}

As summarized in Table 4, Fisher's exact test was conducted to analyze the association between pancreatic stump management and the incidence of POPF. There were significant differences in the incidence of POPF across the groups, with a higher incidence of POPF with the CG occlusion and PPG techniques $(p<0.001)$. The difference in POPF rates between TPG and PPG was nearly significant $(p=0.056)$. Furthermore, the analysis failed to reject the null hypothesis that there was no difference in the rate of POPF between TPG and PJ reconstruction $(p=1.0)$.

The two types of pancreatic reconstruction (TPG or PJ) were significantly correlated with both pancreatic duct diameter $(<3 \mathrm{vs} . \geq 3 \mathrm{~mm}$ ) and texture of the pancreas (friable vs. 


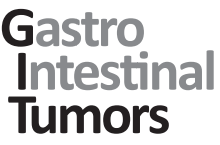

Table 3. Results of the association between POPF and the various predictors

\begin{tabular}{l|l}
\hline Gastrointest Tumors 2018;5:68-76 \\
\hline DOI: 10.1159/000489777 & $\begin{array}{l}\text { @ 2018 S. Karger AG, Basel } \\
\text { www.karger.com/gat }\end{array}$ \\
\hline
\end{tabular}

\begin{tabular}{ll}
\hline & $p$ value \\
\hline ASA score & 0.116 \\
Type 2 diabetes mellitus & 0.137 \\
Pancreatic texture & 0.104 \\
Pancreatic duct diameter & 0.014 \\
Cyanoacrylate glue occlusion & 0.001 \\
\hline
\end{tabular}

ASA, American Society of Anesthesiologists; POPF, postoperative pancreatic fistula.

Table 4. Fisher's exact test to evaluate the incidence of POPF in the four groups

\begin{tabular}{lcccc}
\hline Type of reconstruction & POPF yes, $n(\%)$ & POPF no, $n(\%)$ & $p$ value & $p$ value \\
\hline Total number & 13 & 56 & & \\
TPG & $1(7.69)$ & $27(48.21)$ & $<0.001$ & reference \\
PJ & 0 & $11(19.64)$ & & 1.000 \\
CG occlusion & $9(69.23)$ & $9(17.86)$ & & $<0.001$ \\
PPG & $3(23.08)$ & $8(14.29)$ & & 0.056 \\
\hline
\end{tabular}

CG, cyanoacrylate glue; PJ, pancreaticojejunostomy; POPF, postoperative pancreatic fistula; PPG, posterior pancreaticogastrostomy; TPG, transgastric pancreaticogastrostomy.

hard) ( $p<0.001)$. Most of the individuals with TPG had a pancreatic duct diameter $<3 \mathrm{~mm}$ $(24 / 28)$, and all of them had a friable pancreas $(28 / 28)$. In contrast, a small proportion of individuals with PJ had a pancreatic duct diameter $\geq 3 \mathrm{~mm}(1 / 11)$ and a friable pancreas (2/11).

\section{Discussion}

The safety of pancreatic resections has substantially improved over the last decades; however, POPF still remains a significant problem, with an incidence that varies considerably in the literature, ranging from 10 to 40\% [25-29]. Several reports describe pre- and intraoperative risk factors in the development of POPF, such as friable pancreas and small pancreatic duct [30-34]. The only significant risk factor identified in our series was a pancreatic duct diameter $<3 \mathrm{~mm}$, a finding that is widely supported by the literature [33-37].

The surgical community is making great efforts to provide evidence for the best pancreatic reconstruction $[34,38]$. Recent publications with level 1 evidence have compared the rate of POPF after PJ versus PG. They suggest that PG anastomosis reduces the rate and severity of POPF [34, 37, 39-42]. However, other studies and randomized trials show no difference in the rates of POPF and overall complications $[18,43]$.

PD has been continually adjusted to the evolution of technology, with new technical challenges that were not obvious in the open approach. Despite the initial enthusiasm after the first laparoscopic PD $[44,45]$, this approach was not widely adopted due to longer operative times and the need for advanced laparoscopic skills [8]. Recent reviews have demonstrated that minimally invasive surgery is finding its niche in these complex procedures [8]. Nonetheless, precise patient selection and highly skilled surgeons are crucial 
[8]. Since the first RAPD performed by Giulianotti et al. in 2001 [23], the robotic platform has shown that it can provide certain advantages due to facilitation of technical maneuvers. This allows for a more accurate dissection in narrow operative fields, easier bleeding control, and the possibility of microsuturing. Although PG offers better results than PJ in open surgery [46], there are no studies to date comparing both anastomoses in the robotic approach.

The POPF rate has varied in conjunction with the pancreatic stump management technique used in our case series. The pancreatic reconstruction technique was determined intraoperatively by the primary surgeon, mainly considering the pancreatic texture and duct diameter. The surgeon's experience has also proved to be a decisive variable [47]. In the earlier robotic experience, no pancreatic reconstructions were attempted, and CG occlusion of the pancreatic duct was performed to avoid major complications related with the procedure. Our series showed that CG occlusion of the pancreatic duct was a risk factor for POPF ( $p<0.001)$. In 18 patients who underwent CG occlusion of the pancreatic duct, nine POPFs were registered (50\%). However, the type of fistula expected after this procedure was a pure pancreatic juice fistula that contained enzymes in their inactivated form. Therefore, it is associated with lower risk of surgical reoperation, lower morbidity, and lower mortality [48]. A randomized trial showed better postoperative outcomes of the pure pancreatic fistula [49]. Selected cases, with dilated pancreatic duct and fibrotic pancreas, were completed with the PJ technique, and no POPFs were registered. PPG was introduced as an attempt to improve the POPF rates. Results showed an improvement with a total of three POPFs, but with a higher risk of bleeding. In order to further decrease the number of POPFs, we started using the TPG reconstruction. In our experience, this technique performed with robot assistance provides better control of the pancreatic stump, allowing for greater invagination into the stomach. It also facilitates suturing and stump fixation. Among the 28 patients who underwent TPG reconstruction, there were no clinically significant POPFs (grade B and C). There was 1 case of postoperative bleeding who required an emergent reoperation within the first $24 \mathrm{~h}$.

A comparison between TPG reconstruction and the remaining reconstruction techniques was performed. There were significant differences in the incidence of POPF across the groups. Using TPG reconstruction as a reference, there were significant differences with CG occlusion of the pancreatic duct, showing a higher incidence of POPF in the CG group $(p<0.01)$. This is consistent with the date in the existing literature [50-52]. Hence, we examined TPG versus PJ reconstruction, known as the gold standard technique [41]. There were only one grade A POPF in the TPG group and no POPFs in the PJ group. The data showed comparable results, with no significant differences between groups $(p=1.0)$. In our opinion, this is an important result, since no fistulas were expected in the PJ group, which included all cases of hard pancreatic parenchyma and pancreatic duct diameter $\geq 3 \mathrm{~mm}$, both considered positive characteristics. The fact that the TPG approach, used in the high-risk cases (friable pancreas and pancreatic duct $<3 \mathrm{~mm}$ ), had results similar to those of PJ suggests the validity of the TPG technique. The only limitation of the study is the lack of randomization or a standard criterion with respect to the choice of pancreatic stump management in each patient. It was decided intraoperatively considering multiple variables, which resulted in different groups to analyze. However, power calculation based on Fisher's exact test revealed $80 \%$ power, corresponding to the results rejecting the null hypothesis (Table 3).

In conclusion, pancreatic stump management with PJ and TPG had better results compared to $\mathrm{CG}$ and PPG $(p<0.001$ for comparing TPG+PJ vs. CG+PPG). TPG, performed in patients with POPF risk factors, showed results comparable to those of PJ with regards to the incidence of POPF. Prospective randomized studies with larger sample sizes are needed in order to reach definitive conclusions. 


\section{Disclosure Statement}

P.C. Giulianotti is a consultant for Covidien LP and Ethicon, Inc.; he has a proctoring agreement with Intuitive Surgical. R. Gonzalez-Heredia, S. Durgam, M. Masrur, L.F. Gonzalez-Ciccarelli, A. Gangemi, and F.M. Bianco have no conflicts of interest or financial ties to disclose. No grant funding was obtained for this study.

\section{References}

1 Asbun HJ, Conlon K, Fernandez-Cruz L, Friess H, Shrikhande SV, Adham M, et al: When to perform a pancreatoduodenectomy in the absence of positive histology? A consensus statement by the International Study Group of Pancreatic Surgery. Surgery 2014;155:887-892.

2 Büchler MW, Wagner M, Schmied BM, Uhl W, Friess H, Z'Graggen K: Changes in morbidity after pancreatic resection: toward the end of completion pancreatectomy. Arch Surg 2003;138:1310-1314; discussion 1315.

3 de Castro SM, Busch OR, Gouma DJ: Management of bleeding and leakage after pancreatic surgery. Best Pract Res Clin Gastroenterol 2004;18:847-864.

4 Neoptolemos JP, Russell RC, Bramhall S, Theis B: Low mortality following resection for pancreatic and periampullary tumours in 1026 patients: UK survey of specialist pancreatic units. UK Pancreatic Cancer Group. Br J Surg 1997;84:1370-1376.

5 Denbo JW, Orr WS, Zarzaur BL, Behrman SW: Toward defining grade C pancreatic fistula following pancreaticoduodenectomy: incidence, risk factors, management and outcome. HPB (Oxford) 2012;14:589-593.

6 Addeo P, Delpero JR, Paye F, Oussoultzoglou E, Fuchshuber PR, Sauvanet A, et al: Pancreatic fistula after a pancreaticoduodenectomy for ductal adenocarcinoma and its association with morbidity: a multicentre study of the French Surgical Association. HPB (Oxford) 2014;16:46-55.

7 Grobmyer SR, Kooby D, Blumgart LH, Hochwald SN: Novel pancreaticojejunostomy with a low rate of anastomotic failure-related complications. J Am Coll Surg 2010;210:54-59.

8 Liao CH, Wu YT, Liu YY, Wang SY, Kang SC, Yeh CN, et al: Systemic review of the feasibility and advantage of minimally invasive pancreaticoduodenectomy. World J Surg 2016;40:1218-1225.

9 Braga M, Capretti G, Pecorelli N, Balzano G, Doglioni C, Ariotti R, et al: A prognostic score to predict major complications after pancreaticoduodenectomy. Ann Surg 2011;254:702-707; discussion 707-708.

10 Polanco PM, Zenati MS, Hogg ME, Shakir M, Boone BA, Bartlett DL, et al: An analysis of risk factors for pancreatic fistula after robotic pancreaticoduodenectomy: outcomes from a consecutive series of standardized pancreatic reconstructions. Surg Endosc 2016;30:1523-1529.

11 Shubert CR, Wagie AE, Farnell MB, Nagorney DM, Que FG, Reid Lombardo KM, et al: Clinical risk score to predict pancreatic fistula after pancreatoduodenectomy: independent external validation for open and laparoscopic approaches. J Am Coll Surg 2015;221:689-698.

12 Hosotani R, Doi R, Imamura M: Duct-to-mucosa pancreaticojejunostomy reduces the risk of pancreatic leakage after pancreatoduodenectomy. World J Surg 2002;26:99-104.

13 van Berge Henegouwen MI, De Wit LT, Van Gulik TM, Obertop H, Gouma DJ: Incidence, risk factors, and treatment of pancreatic leakage after pancreaticoduodenectomy: drainage versus resection of the pancreatic remnant. J Am Coll Surg 1997;185:18-24.

14 El Nakeeb A, El Hemaly M, Askr W, Abd Ellatif M, Hamed H, Elghawalby A, et al: Comparative study between duct to mucosa and invagination pancreaticojejunostomy after pancreaticoduodenectomy: a prospective randomized study. Int J Surg 2015;16:1-6.

15 Kaman L, Sanyal S, Behera A, Singh R, Katariya RN: Isolated Roux loop pancreaticojejunostomy vs single loop pancreaticojejunostomy after pancreaticoduodenectomy. Int J Surg 2008;6:306-310.

16 Winter JM, Cameron JL, Campbell KA, Chang DC, Riall TS, Schulick RD, et al: Does pancreatic duct stenting decrease the rate of pancreatic fistula following pancreaticoduodenectomy? Results of a prospective randomized trial. J Gastrointest Surg 2006;10:1280-1290; discussion 1290.

17 Fernandes E, Giulianotti PC: Robotic-assisted pancreatic surgery. J Hepatobiliary Pancreat Sci 2013;20:583589.

18 Bassi C, Falconi M, Molinari E, Salvia R, Butturini G, Sartori N, et al: Reconstruction by pancreaticojejunostomy versus pancreaticogastrostomy following pancreatectomy: results of a comparative study. Ann Surg 2005; 242:767-771; discussion 771-773.

19 Palanivelu C, Rajan PS, Rangarajan M, Vaithiswaran V, Senthilnathan P, Parthasarathi R, et al: Evolution in techniques of laparoscopic pancreaticoduodenectomy: a decade long experience from a tertiary center. J Hepatobiliary Pancreat Surg 2009;16:731-740.

20 Croome KP, Farnell MB, Que FG, Reid-Lombardo KM, Truty MJ, Nagorney DM, et al: Total laparoscopic pancreaticoduodenectomy for pancreatic ductal adenocarcinoma: oncologic advantages over open approaches? Ann Surg 2014;260:633-638; discussion 638-640.

21 Bao PQ, Mazirka PO, Watkins KT: Retrospective comparison of robot-assisted minimally invasive versus open pancreaticoduodenectomy for periampullary neoplasms. J Gastrointest Surg 2014;18:682-689. 
22 Gagner M, Palermo M: Laparoscopic Whipple procedure: review of the literature. J Hepatobiliary Pancreat Surg 2009;16:726-730.

23 Giulianotti PC, Coratti A, Angelini M, Sbrana F, Cecconi S, Balestracci T, et al: Robotics in general surgery: personal experience in a large community hospital. Arch Surg 2003;138:777-784.

24 Bassi C, Dervenis C, Butturini G, Fingerhut A, Yeo C, Izbicki J, et al: Postoperative pancreatic fistula: an international study group (ISGPF) definition. Surgery 2005;138:8-13.

25 Kawai M, Kondo S, Yamaue H, Wada K, Sano K, Motoi F, et al: Predictive risk factors for clinically relevant pancreatic fistula analyzed in 1,239 patients with pancreaticoduodenectomy: multicenter data collection as a project study of pancreatic surgery by the Japanese Society of Hepato-Biliary-Pancreatic Surgery. J Hepatobiliary Pancreat Sci 2011;18:601-608.

26 Kawai M, Tani M, Terasawa H, Ina S, Hirono S, Nishioka R, et al: Early removal of prophylactic drains reduces the risk of intra-abdominal infections in patients with pancreatic head resection: prospective study for 104 consecutive patients. Ann Surg 2006;244:1-7.

27 Fernandez-del Castillo C, Rattner DW, Warshaw AL: Standards for pancreatic resection in the 1990s. Arch Surg 1995;130:295-299; discussion 299-300.

28 Tani M, Kawai M, Hirono S, Okada KI, Miyazawa M, Shimizu A, et al: Randomized clinical trial of isolated Rouxen-Y versus conventional reconstruction after pancreaticoduodenectomy. Br J Surg 2014;101:1084-1091.

29 Pedrazzoli S, Liessi G, Pasquali C, Ragazzi R, Berselli M, Sperti C: Postoperative pancreatic fistulas: preventing severe complications and reducing reoperation and mortality rate. Ann Surg 2009;249:97-104.

30 Ansorge C, Strommer L, Andren-Sandberg A, Lundell L, Herrington MK, Segersvard R: Structured intraoperative assessment of pancreatic gland characteristics in predicting complications after pancreaticoduodenectomy. Br J Surg 2012;99:1076-1082.

31 Belyaev O, Munding J, Herzog T, Suelberg D, Tannapfel A, Schmidt WE, et al: Histomorphological features of the pancreatic remnant as independent risk factors for postoperative pancreatic fistula: a matched-pairs analysis. Pancreatology 2011;11:516-524.

32 Belyaev O, Herden H, Meier JJ, Muller CA, Seelig MH, Herzog T, et al: Assessment of pancreatic hardness surgeon versus durometer. J Surg Res 2010;158:53-60.

33 Liu QY, Zhang WZ, Xia HT, Leng JJ, Wan T, Liang B, et al: Analysis of risk factors for postoperative pancreatic fistula following pancreaticoduodenectomy. World J Gastroenterol 2014;20:17491-17497.

34 Guerrini GP, Soliani P, D’Amico G, Benedetto FD, Negri M, Piccoli M, et al: Pancreaticojejunostomy versus pancreaticogastrostomy after pancreaticoduodenectomy: an up-to-date meta-analysis. J Invest Surg 2016;29: 175-184.

35 Callery MP, Pratt WB, Kent TS, Chaikof EL, Vollmer CM Jr: A prospectively validated clinical risk score accurately predicts pancreatic fistula after pancreatoduodenectomy. J Am Coll Surg 2013;216:1-14.

36 Fuks D, Piessen G, Huet E, Tavernier M, Zerbib P, Michot F, et al: Life-threatening postoperative pancreatic fistula (grade C) after pancreaticoduodenectomy: incidence, prognosis, and risk factors. Am J Surg 2009;197: 702-709.

37 Zhang X, Ma L, Gao X, Bao H, Liu P, Aziz A, et al: Pancreaticogastrostomy versus pancreaticojejunostomy reconstruction after pancreaticoduodenectomy: a meta-analysis of randomized controlled trials. Surg Today 2015; 45:585-594.

38 Yardimci S, Kara YB, Tuney D, Attaallah W, Ugurlu MU, Dulundu E, et al: A simple method to evaluate whether pancreas texture can be used to predict pancreatic fistula risk after pancreatoduodenectomy. J Gastrointest Surg 2015;19:1625-1631.

39 Que W, Fang H, Yan B, Li J, Guo W, Zhai W, et al: Pancreaticogastrostomy versus pancreaticojejunostomy after pancreaticoduodenectomy: a meta-analysis of randomized controlled trials. Am J Surg 2015;209:1074-1082.

40 Sledzinski Z, Kostro JZ, Zadrozny D, Pirski I, Lukianski M, Glowacki J: Results of pancreaticogastrostomy after pancreaticoduodenectomy in 159 consecutive cases. Pancreatology 2008;8:36-41.

41 Topal B, Fieuws S, Aerts R, Weerts J, Feryn T, Roeyen G, et al: Pancreaticojejunostomy versus pancreaticogastrostomy reconstruction after pancreaticoduodenectomy for pancreatic or periampullary tumours: a multicentre randomised trial. Lancet Oncol 2013;14:655-662.

42 Xiong JJ, Tan CL, Szatmary P, Huang W, Ke NW, Hu WM, et al: Meta-analysis of pancreaticogastrostomy versus pancreaticojejunostomy after pancreaticoduodenectomy. Br J Surg 2014;101:1196-1208.

43 Grendar J, Ouellet JF, Sutherland FR, Bathe OF, Ball CG, Dixon E: In search of the best reconstructive technique after pancreaticoduodenectomy: pancreaticojejunostomy versus pancreaticogastrostomy. Can J Surg 2015; 58:154-159.

44 Palanivelu C, Jani K, Senthilnathan P, Parthasarathi R, Rajapandian S, Madhankumar MV: Laparoscopic pancreaticoduodenectomy: technique and outcomes. J Am Coll Surg 2007;205:222-230.

45 Dulucq JL, Wintringer P, Mahajna A: Laparoscopic pancreaticoduodenectomy for benign and malignant diseases. Surg Endosc 2006;20:1045-1050.

46 Menahem B, Guittet L, Mulliri A, Alves A, Lubrano J: Pancreaticogastrostomy is superior to pancreaticojejunostomy for prevention of pancreatic fistula after pancreaticoduodenectomy: an updated meta-analysis of randomized controlled trials. Ann Surg 2015;261:882-887.

47 Kleespies A, Albertsmeier M, Obeidat F, Seeliger H, Jauch KW, Bruns CJ: The challenge of pancreatic anastomosis. Langenbecks Arch Surg 2008;393:459-471. 
48 Violi V, Salvemini C, Darecchio A, Detullio P, Costi R: Pure pancreaticocutaneous fistula shunted into the urinary bladder. Lesson learned by an incomplete, original attempt. Int Surg 2014;99:258-263.

49 Reissman P, Perry Y, Cuenca A, Bloom A, Eid A, Shiloni E, et al: Pancreaticojejunostomy versus controlled pancreaticocutaneous fistula in pancreaticoduodenectomy for periampullary carcinoma. Am J Surg 1995;169: 585-588.

50 Cheng Y, Ye M, Xiong X, Peng S, Wu HM, Cheng N, et al: Fibrin sealants for the prevention of postoperative pancreatic fistula following pancreatic surgery. Cochrane Database Syst Rev 2016;2:CD009621.

51 Mauriello C, Polistena A, Gambardella C, Tartaglia E, Orditura M, De Vita F, et al: Pancreatic stump closure after pancreatoduodenectomy in elderly patients: a retrospective clinical study. Aging Clin Exp Res 2017;29(suppl 1):S35-S40.

52 Conzo G, Gambardella C, Tartaglia E, Sciascia V, Mauriello C, Napolitano S, et al: Pancreatic fistula following pancreatoduodenectomy. Evaluation of different surgical approaches in the management of pancreatic stump. Literature review. Int J Surg 2015;21(suppl 1):S4-S9. 